\title{
INTRODUCTION
}

\section{The Postponement of Childbearing in Europe: Driving Forces and Implications}

\author{
Francesco C. Billari, Aart C. Liefbroer, and Dimiter Philipov*
}

\section{Introduction}

Postponement has been a major keyword in the description and the study of demographic trends observed in developed countries during the last decades. With few exceptions, during the recent decades demographic events such as those leading to the formation of new households and families have occurred later and later in the lives of women and men. Although considerable heterogeneity exists both between and within countries in this general pattern of postponement, almost everywhere in the developed world events such as leaving the parental home, forming a new union, getting married and becoming a parent are being experienced on average later in life than ever before. Postponement has been particularly important in understanding the fertility decline observed across Europe over the last few decades. As Table 1 makes clear, such postponement has been pervasive, with increases in the mean age at first birth of the order of magnitude of three or four years during the 1980-2004 period (with the exception of Russia). Correspondingly, also the general mean age at childbearing has increased.

As a consequence of the observation of these stylised facts, understanding the causes and consequences of fertility postponement has been high on the demographic research agenda. However, many open questions still remain: How exactly should postponement be defined and measured? What is its effect on fertility levels? How does it interact with other life course events? What are its bio-medical and socio-economic dimensions? And, finally, what are the consequences, and should governments intervene with adequate policies? These

\footnotetext{
* Francesco C. Billari (author for correspondence), "Carlo F. Dondena" Centre for Research on Social Dynamics, IGIER and IMQ, Università Bocconi, Milan, Italy.

E-mail: francesco.billari@uni-bocconi.it.

Aart C. Liefbroer, Netherlands Interdisciplinary Demographic Institute (NIDI), The Hague, The Netherlands and Department of Social Research Methodology, Vrije Universiteit Amsterdam, The Netherlands

Dimiter Philipov, Vienna Institute of Demography, Austrian Academy of Sciences, Vienna, Austria.
} 
were some of the issues discussed at the International Conference on the Postponement of Childbearing in Europe that took place in Vienna, 1-3 December 2005, organised by the Vienna Institute of Demography of the Austrian Academy of Sciences, Università Bocconi, and the International Institute for Applied Systems Analysis in collaboration with the Working Group on the Second Demographic Transition in Europe of the European Association for Population Studies on the premises of Statistics Austria. The articles in this Special Issue of the Vienna Yearbook of Population Research result from a peer-reviewed selection of the papers presented at what proved to be a particularly successful scientific meeting. This introduction is meant to provide a general overview of the issues at stake and to highlight the contributions that the articles in this volume make to our understanding of these issues.

Table 1:

Mean age at first birth, mean age at childbearing and total fertility rate for selected countries from different regions in Europe, 1980 and 2004

\begin{tabular}{lcccccc}
\hline & \multicolumn{2}{c}{ Mean age at first birth } & \multicolumn{2}{c}{ Mean age at childbearing } & \multicolumn{2}{c}{ Total fertility rate } \\
& 1980 & 2004 & 1980 & 2004 & 1980 & 2004 \\
\hline Bulgaria & 21.9 & 24.4 & 23.9 & 25.7 & 2.05 & 1.29 \\
Czech Republic & 22.4 & 26.3 & 24.7 & 28.3 & 2.10 & 1.22 \\
Netherlands & 25.7 & 28.9 & 27.7 & 30.5 & 1.60 & 1.73 \\
Russia & 23.0 & 24.0 & 25.7 & 25.9 & 1.86 & 1.33 \\
Spain & 25.0 & 29.3 & 28.2 & 30.9 & 2.20 & 1.32 \\
Sweden & 25.3 & 28.6 & 27.6 & 30.4 & 1.68 & 1.75 \\
\hline
\end{tabular}

The structure of this introductory article is as follows. Section 2 deals with the causes, i.e., the forces driving the postponement of childbearing. Instead of presenting an overview of all relevant factors, we will limit our discussion to a few major driving forces, namely ideational change, the rise of women's human capital and the increase in uncertainty coupled with policy changes. Section 3 deals with the consequences of the postponement of childbearing. Both aggregatelevel (and measurement) and micro-level implications are discussed. The social and economic relevance of the potential consequences of postponement has led to an increased awareness about these issues among policy makers. Section 4 discusses the need for, and feasibility of, policy measures to counteract these potential consequences. Finally, some concluding remarks on promising future avenues for research will be made in Section 5. In each section, the contribution of articles included in this issue will be highlighted. The order of subsequent articles in the issue therefore reflects our (completely subjective) reading path, as outlined in this introduction. 


\section{On the Driving Forces of Postponement}

What are the main driving forces behind the postponement of childbearing? Clearly, a comprehensive review of the issue is outside the scope of this introduction. Numerous factors have been identified in the literature (see, e.g., Sobotka 2004a, for a review and references). In what follows, we focus on three of the main driving forces only. First, we discuss ideational change and how the idea of a "Second Demographic Transition" relates to the postponement of childbearing. Second, we point to the crucial importance of increasing female human capital accumulation. Third, we comment on the potential role of uncertainty, both from an economic point of view and as expressed by anomy, and policy changes related to rising economic insecurity that might shape postponement especially in central and eastern Europe.

\subsection{The Second Demographic Transition and the Postponement of Childbearing}

The general trend towards postponement is an important element of the concept of Second Demographic Transition (SDT). According to the proponents of the SDT concept, whose usefulness had been subject to debate in the 2004 edition of the Vienna Yearbook, the transition started in northern Europe during the 1960s and has since diffused across the industrialised world (Lesthaeghe and Van de Kaa 1986; Van de Kaa 1987; Lesthaeghe 1995). The SDT framework suggests that demographic changes, including postponement of childbearing, are to a large extent due to ideational shifts, in particular to the increased emphasis on individual autonomy, the rejection of institutional control, the rise of values associated with the satisfaction of individuals' 'higher-order needs', and the growth in gender equality (see, e.g., Surkyn and Lesthaeghe 2004). These ideational changes have led to the emergence of 'postmodern fertility preferences' (Van de Kaa 2001).

These same themes appear in the sociological literature, where the emergence of 'new' family behaviour (like cohabitation and non-marital childbearing) has been considered one of the signs of a process of individualisation of life courses as well as an aspect of the evolution of western European and North American societies towards a new modernity (Buchmann 1989; Beck 1992; Giddens 1990). The SDT and the 'new modernity' ideas share a 'developmental' perspective on societal change: societies are assumed to develop through a sequence of stages leading in a certain direction. This concept, intertwined with the notion of 'transition', has had a strong impact on demographic research (Thornton 2001).

The centrality of fertility postponement with the SDT is evidenced by Van de Kaa (1997). Based on observations on the 1965-1995 period, Van de Kaa postulates that the SDT is constituted by a complex set of sequences of stages. He identifies 15 stages, some of which are explicitly connected to the postponement 
of childbearing. In stage 2, premarital pregnancies are avoided. In stage 4 , childbearing within marriage is postponed, with a decline of fertility among young women that accentuates the decline in period TFR (see also the discussion in Section 3). Much later on, in stage 12, the period TFR increases slightly because births by women who postponed childbearing lead to an increase in lower-order birth rates at higher ages. However, not all postponed births can be realised (stage 13), and voluntary childlessness becomes significant (stage 14). This sequence of stages seems to correspond empirically to current developments in Europe.

Although the idea that fertility postponement is linked to ideational change is enticing, most empirical research only offers correlational evidence. For instance, Surkyn and Lesthaeghe (2004) find a correlation between value orientations and family choices using data from the European Values Study. However, panel studies in which the actual childbearing behaviour is observed after values have been measured, offer much stronger evidence that values actually influence fertility behaviour. An example is Liefbroer (2005), who documents that the transition to parenthood is postponed among young adults who value individual autonomy and think that having a child will negatively influence their autonomy. The contribution to this volume by Bernhardt and Goldscheider (2006) offers another useful illustration that "values matter". Their article focuses on Sweden, which is in the words of its authors "perhaps the furthest among the countries that have entered the Second Demographic Transition". It studies the relationship between gender equality, attitudes towards parenthood and timing of first births. They show that men who are not holding traditional attitudes towards gender equality tend to postpone childbearing as compared to those who do hold traditional attitudes. No such effect is found for women. The finding that egalitarian attitudes delay the transition to parenthood is therefore consistent with the SDT idea that ideational change goes hand in hand with the postponement of childbearing.

Although Testa and Toulemon (2006, this volume) study the role of a more proximate determinant of postponement, i.e., fertility intentions, their contribution to this issue also documents the important role played by subjective ideas in determining fertility decisions. People who intend or expect to have a child within five years are much more likely to actually become parents within that time-span than people who do not intend or expect to do so. Interestingly, this relationship is much stronger among highly educated respondents than among respondents with a low level of education, suggesting that the 'planning capacities' of the former are better than those of the latter.

\subsection{The Rise of Women's Education}

Another frequently discussed driving force behind the postponement of fertility is the rise in women's educational attainment. Several mechanisms that cause higher 
educated women to delay motherhood have been put forward. Economic models of the timing of first births (e.g., Happel et al. 1984; Gustafsson 2001) predict that the higher the woman's educational level, the later her transition to motherhood. The basic premise in these models is that the focus of decision-making in the transition to motherhood is on timing, and that opportunity costs of childbearing and subsequent long-term financial consequences of motherhood depend on the age at motherhood. An additional mechanism that connects educational level and fertility (Cigno and Ermisch 1989) in such models is that the higher the level of returns to education, the later the transition to motherhood. Empirical findings support this economic perspective: Gustafsson et al. (2002), for instance, show that in Germany, Great Britain and Sweden higher-educated women become mothers at a later age, and that they were the first to start postponing first births.

The importance of educational enrolment, i.e., of being a student, next to that of level of educational attainment, in explaining postponement of childbearing is emphasised by a stream of papers that are mostly based on sociological theories adopting a life-course perspective and on empirical studies based on event history analysis. Blossfeld and Huinink (1991) suggest that "...When a woman is attending school, university (...) she is economically highly dependent on her parents. Further, there exist normative expectations in society that young people who attend school are 'not at risk' of entering marriage (and having children)..." Educational enrolment is thus hypothesised to have a direct effect on postponement in so far as during their period of study people concentrate their time and energy on studying and not on starting a family. Using a different theoretical framework, Kravdal (1994) finds that in Norway the effects of the educational level on the transition to motherhood are small when compared to the effects of being enrolled in education or, more specifically, work experience. Further theoretical arguments, together with empirical analyses of the impact of school enrolment on young adults' family formation are presented by Thornton et al. (1995), who show that human capital accumulation also influences the choice of marital versus non-marital first union, and by Liefbroer and Corijn (1999).

Given the consistency of the various findings in the literature, trends in female education can be seen as a major force shaping the postponement of childbearing in Europe. In most European countries, educational enrolment is scarcely compatible with childbearing, even if the length of education is in part determined by the same factors that drive the timing of first birth, and even if the extent of incompatibility differs between countries (Billari and Philipov 2004). Moreover, trends in educational expansion are correlated with the ideational change that has been previously discussed as accompanying the SDT, i.e., both driving forces push in the same direction. 


\subsection{Uncertainty During Young Adulthood and Policy Changes}

The imaginary 'Hajnal' line (Hajnal 1965) cuts across Europe, connecting Saint Petersburg and Trieste. This line, from a historical perspective, separated a region with earlier and more universal marriage and childbearing to the east, and a region with later and less universal marriage and childbearing to the west. Also during the more recent period between World War II and the fall of the Iron Curtain, this line proved to be an important way of describing differentials in Europe (Monnier and Rychtarikova 1992). West of the Hajnal line, fertility at the beginning of reproductive ages was low, whereas that was not the case east of the line. However, during the 1990s, the postponement of childbearing hit also to the east of the Hajnal line, with the partial exception of the Russian Federation (see Table 1).

While insecurity during young adult years has been mentioned as an important driver of the postponement of childbearing in southern Europe (see, e.g., Kohler et al. 2002), and perceived uncertainty has been shown to influence the postponement to parenthood in the Netherlands (Liefbroer 2005), uncertainty is supposed to have become of primary importance for the transition economies of central and eastern Europe. In most of these transition economies, fertility declined very steeply during the 1990 s, here immediately following the fall of socialist regimes, there with delay of a few years (UNECE 2000; Macura and MacDonald 2003; Philipov and Dorbritz 2003). The spread of uncertainty in young adulthood, for instance as a result of increasingly difficult access to the labour market, in combination with other factors, such as increases in the return to education, may explain period trends and international differentials in family formation (Bernardi 2000). Under conditions of economic uncertainty, people's income becomes less reliable, and people are likely to postpone childbearing until their income becomes more stable and reliable (Blossfeld et al. 2005). In fact, Kohler et al. (2002) argue that postponement of the transition to parenthood may arise as a rational response to such socio-economic changes. The evidence for this in relation to the sharp fertility decline in eastern Europe is, however, still ambiguous (Kohler and Kohler 2002). Ranjan (1999) and Bhaumik (2002) find uncertainty to be one of the key factors that contributed to the drastic fall in fertility in former East Germany during the first half of the 1990s. Philipov et al. (2006), in an analysis of fertility intentions in Bulgaria and Hungary, document that uncertainty might be reinforced by anomy and disorientation, factors that both contribute to the postponement of childbearing.

An additional factor that might have driven postponement in central and eastern Europe is related to policy changes, or to the uncertainty surrounding specific policies. Aassve et al. (2006) analyse the impact of the transition from a universal to a means-tested type of family allowance in Hungary during the mid1990s. The impact of the policy change was to broaden the age gap in the transition to motherhood between high and low social strata (as represented by 
educational levels). As soon as the family allowance became universal again, the differences returned to their initial level.

\section{Consequences of the Postponement of Childbearing}

The social and economic significance of the postponement of childbearing is strongly connected to its consequences at the individual and at the societal level. It is hardly surprising, also given the nature of the initial call for papers, that this special issue contains a majority of papers dealing with the consequences of the postponement of childbearing rather than with the driving factors. All authors agree that having children later in life has consequences for individuals, i.e., micro-level life-course implications. At the same time, postponement also has consequences for the demographic structure of a population, as well as for the way we measure fertility at the aggregate level. We now discuss these various sets of implications one by one.

\subsection{Micro-Level Implications}

One of the key implications of the contemporary postponement of fertility at the individual and couple level is its effect on total fertility: a later start, ceteris paribus, might result in having fewer children. While, in a cross-section of countries, often no specific macro-level relationship between mean age at first birth and the period total fertility rate is observed (see, e.g., Dalla Zuanna 2001), the literature has repeatedly documented the existence of a postponement effect on fertility at the individual level. Ultimately, voluntary postponement may lead to involuntary childlessness. Kohler and Ortega (2002) introduced in this setting the aggregate-level notion of fertility ageing effect, defined as the reduction in higherorder births (or parity progression ratios) caused by a postponement of fertility at first (or second) births, to study the interaction between the timing and quantum of fertility (see below).

The micro-level postponement effect is, however, of different magnitude in different settings: in Kohler et al. (2002) the postponement effect is an important mechanism that contributes to decreasing the quantum of fertility in countries with lowest-low fertility levels. More specifically, postponing first births has a particularly important impact on quantum fertility in those societies where institutional arrangements such as labour market regulations, childcare system and gender relationships make it more problematic for women to combine family life and occupational careers. Southern European countries, for instance, show a higher postponement effect than northern European countries such as Sweden. An empirical example of the individual-level postponement effect is given in Figure 1, from Billari and Borgoni (2005), where the (predicted) completed fertility of a woman is related to her age at first birth. 
Figure 1:

Predicted completed fertility for a woman by age at first birth

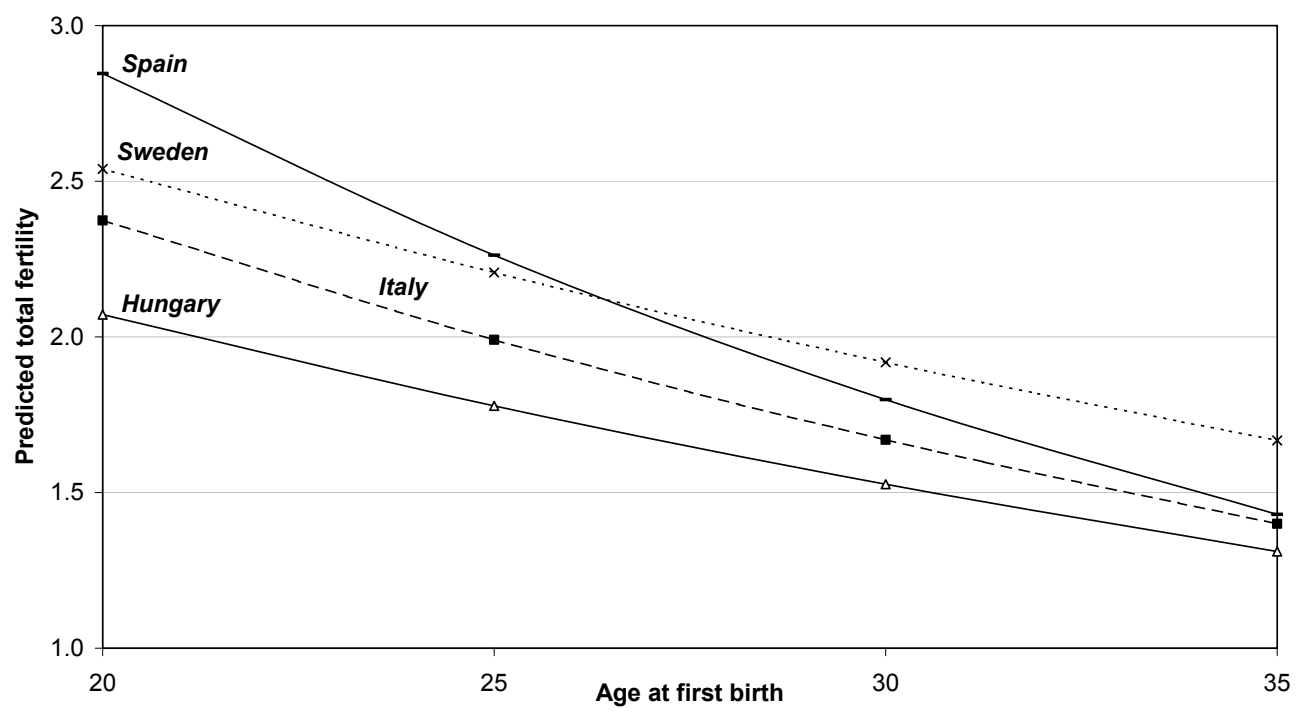

Source: Billari and Borgoni (2005)

The postponement of births matters for its relationships with opportunity costs; however it has implications on biological clocks and other changes that are influenced by age. Fecundability has been shown to decline with age, both for men and for women (i.e., Larsen and Vaupel 1993; Dunson et al. 2002). Leridon (2004) estimates that in non-contracepting populations the mean age at the onset of women's sterility is 44.7 years. The potential inability to realise one's own childbearing plans as a consequence of fertility postponement is investigated from a behavioural perspective by Rizzi and Rosina (2006, this volume). Age-specific fecundability, i.e., the probability of conception in a given period for sexually active couples not using contraception, is known to decline by age. Using a unique and purposely collected data set, the "Multinational Study on Daily Fecundability" (Colombo and Masarotto 2000), Rizzi and Rosina show that the frequency of sexual intercourse declines with age, and that the desire to have a child seems to compensate only partially for the effect of the decrease in coital frequency. The micro-level effect of the postponement of childbearing on total fertility is therefore not only due to the physiological decline of fecundability with age, but also to the proximate behavioural determinant, i.e., sexual behaviour.

A second set of micro-level consequences of postponement relates to pregnancy and birth outcomes. Leridon (2005), for instance, documents the impact of age on the ability to carry a pregnancy to term after successful conception: his estimates of the probability of a miscarriage reach $20 \%$ at age 37 , $30 \%$ at age 44 , and $40 \%$ at age 48 . Matsuo (2006, this volume) focuses on the consequences of giving birth later in life for the child's health. Her findings 
from the analysis of two longitudinal datasets from Belgium confirm former analyses and show that the higher the maternal age, the higher the risk of adverse health outcomes for the child (i.e., low birth weight and slower weight gain after birth). Such adverse health outcomes are particularly likely if mothers get children beyond age 40 .

While not explicitly addressed in this volume, it is important to stress that there exists a literature on potentially positive individual-level consequences of the postponement of childbearing. The main, and fiercely debated, issue is about the relationship between age at birth, for a given parity, and longevity. For instance, Müller et al. (2002) claim that "late children enhance female longevity", reporting from an analysis of historical data that a mother's life expectation increases when she gives birth later. Yi and Vaupel (2004) document that childbearing after age 35 or 40 is positively associated with survival among Chinese women and men. However, a later age at (last) birth might be an indicator of later age at sterility (McArdle et al. 2006). Mueller (2004), on the contrary, in an analysis of a dataset on European royalty finds that later reproduction did not extend the life span. Although inconclusive, this literature raises the awareness that researchers should be careful in suggesting that the micro-level consequences of postponement are necessarily bad. What is more needed instead is a careful consideration of the consequences of postponement for all relevant life domains and for all people (parents and children) involved.

\subsection{Fertility Measurement and Macro-Level Implications}

According to Morgan and Taylor (2006, p. 378), "a key question is whether aggregate fertility change (in a given period) reflects fertility postponement (timing) or a change in the number of births women will have (quantum)". Measuring the postponement of fertility is crucial for studying contemporary fertility because of its analytical (and, potentially, policy) consequences. In the presence of a widespread postponement of births, traditional period fertility measures have to be interpreted with great care.

Period total fertility rates, which have been used to define the threshold of lowest-low fertility, are rightly criticised in the literature for being subject to various types of distortion. This problem was long debated in the fertility literature, but has been revived in recent years by the contribution of Bongaarts and Feeney (1998). Different proposals have been made over the last few years for how to compute a distortion-free measure of period fertility, which can give a better interpretation of behavioural choices (see the review in Ortega and Kohler 2002). Bongaarts and Feeney (2006, this volume) generalise their original 1998 framework for the analysis of tempo and quantum of childbearing to all life course events. They develop and apply methods to remove tempo distortions to various measures, including those derived from life tables. 
The discussion on the measurement of fertility has also stimulated reflection on the potential limits to postponement. Sobotka (2004b, p. 212), for instance, describes lowest-low fertility in Europe as a "result of increasing age at motherhood and, therefore, a temporary phenomenon that will fade once the postponement of childbearing stops". While individual-level limits to postponement have to be related to the possibility to bear children at advanced ages (Billari et al. 2006), and are therefore connected to the micro-level consequences of postponement discussed in Section 3.1, aggregate-level limits to postponement have so far not been explicitly addressed in the literature. Goldstein (2006, this volume) presents the results of a simulation study based on transformations of actual fertility schedules by age at first birth for Danish women born 1963. Under a set of what seem to be realistic hypotheses, Goldstein finds that a mean age at first birth of about 33 years is plausible, implying that postponement can continue in the near future without radical changes in individual-level limits.

Although period measures of fertility have been criticised, we cannot do without them if we want to study what is currently happening and grasp changes in trends (Ní Bhrolchain 1992). Calot (2001), for instance, advocates the use of the period total fertility rate to measure the ratio of the size of the newborn generation to the generation of mothers. A synthetic indicator of this type reflects the joint effect of the number of births, population age structure, population ageing, and cohort replacement, and thus brings forward a central role for period fertility. At the same time, one has to reflect upon the long-term consequences of postponement for future fertility levels. Lutz, Skirbekk and Testa (2006, this volume) deal with a potential mechanism that would induce a continued decline in the number of births, i.e., a low fertility trap. The mechanism is built around three components. First, because of the so-called negative momentum of population growth, the decrease in the number of births would continue at least for a period even in the presence of an increase in period fertility (see also Lutz et al. 2003). Second, personal ideal family sizes might decline if they are influenced by current fertility level. Third, a decline in relative income (Easterlin 1980) might contribute further to depress fertility. In conjunction, all these mechanisms could induce a situation in which a future increase of fertility level would become highly unlikely. Postponement might have a self-reinforcing dynamics that transcends the reasons that triggered it. This mirrors an argument, developed by Kohler et al. (2002), that what we are observing is actually a postponement transition which is likely to be irreversible. Evidence for this irreversibility is given in analogy to what has been shown for the fertility decline during the demographic transition, with the pace of postponement of first birth developing in a similar manner in different countries even if the postponement starts in different years. 


\section{Policy Implications}

The theoretical model presented in this volume by Lutz, Skirbekk and Testa (2006) brings us the potential policy implications of the postponement of childbearing. At the macro level, postponement matters insofar as it influences completed fertility and the size of birth cohorts. So far we have seen that the general evidence points to a significant causal role of the postponement of childbearing in completed fertility derived from the micro level. The Green Paper "Confronting demographic change: a new solidarity between generations" issued in 2005 by the European Commission indeed recognises the role of the postponement of childbearing in shaping completed fertility, one of the basic trends that are targeted by European policy-makers: "The baby-boomer generation has had fewer children than previous generations, as a result of many factors: difficulties in finding a job, the lack and cost of housing, the older age of parents at the birth of their first child, different study, working life and family life choices" (Commission of the European Communities 2005, p. 3).

The postponement of childbearing has also specific implications on population ageing. Lutz, O'Neill and Scherbov (2003, p. 1992), for instance, compute that "[t]wenty years of continued increases in the mean age of childbearing imply an additional decline in the support ratio of about 0.5 workers per elderly person by 2065 , the year when the difference is most pronounced". For these reasons, some scholars have suggested that policies explicitly take the timing of births as a target, promoting policies that allow counterbalancing, if not reversing, the postponement of childbearing. These ideas, labelled tempo policies, have been described by Lutz and Skirbekk (2005) as a means to avoid a lowfertility trap. An exemplary tempo policy is one that shortens the period spent in education: taking for granted the results mentioned in Section 2.2 on the importance of having completed education as a prerequisite for family formation, shortening educational timetables might allow for earlier family formation. An alternative, or possibly complementary approach, would call for policies that allow an easier combination of education and family formation (Billari and Philipov 2004).

These examples make it clear that whether fertility-related policies are contemplated or not depends crucially on the assessment of the consequences of these trends. This is an important reason for research that focuses on the individual and societal consequences of postponement. At the same time, policies will only be effective if the causes of these trends are well understood and if policies can either change people's preferences regarding the timing of parenthood or the opportunity structure that hampers the realisation of people's preferences. Therefore, knowledge on the relative weight of each driving force does not only carry importance for researchers who aim at evaluating the main causes behind postponement, but may also lead to different policy implications (Hantrais et al. 2006). 
The aim and content of policies that might affect the timing (and quantum) of childbearing is discussed in two articles in this issue. Van de Kaa (2006, this volume) discusses why governments are 'prudent' in considering pro-natal policies. His reasoning on the centrality and effectiveness of policies aimed at supporting birth rates is based on a series of related arguments, inter alia that (a) governments usually give first priority to structural reforms, (b) the scientific evidence on the effectiveness of pronatalist policies on fertility is weak, (c) population policies enjoy a bad reputation because of their misuse by undemocratic regimes in the past, and (d) future social change might lead to a reversal in fertility. However, McDonald (2006, this volume) states that it is too risky "to wait for a homeostatic correction to low fertility" and that the introduction by governments of relevant policies to increase births is inescapable. $\mathrm{He}$ addresses systematically a series of principles that should guide policies aimed at supporting the birth rate. He is, however, rather sceptical about policies explicitly targeting the timing of births, and in particular does not support a possible age-selectivity of monetary benefits connected to childbearing.

\section{On Future Research on the Postponement of Childbearing}

What this introduction, and in particular the various contributions to this volume, will make clear, is that the postponement of childbearing involves a heterogeneous but interconnected and highly relevant set of topics on which further research is greatly needed.

For what concerns the driving forces of postponement, future research will have to try to weight the relative importance of the different factors that contribute to childbearing postponement. New efforts in the collection of data that allow a potentially multidisciplinary approach to fertility decision-making are in place, and we expect them to be fruitful in future research. In particular, the Generations and Gender Survey, which is part of a broader Generations and Gender Program, should allow the evaluation of the weight of different factors in a diverse set of contexts (see Vikat et al. 2006). Special attention, in this regard, should be given to research that tries to establish whether effects are causal or spurious. This is particularly true when the impact of policy changes on the postponement of childbearing is being evaluated. Still within the domain of driving forces, and given the high levels of diversity both across and within societies, we expect future research to give particular attention to micro-macro interaction, i.e., to the way context shapes the relationships between specific drivers and the decision to postpone childbearing (Lesthaeghe 1998).

Studies on the micro- and macro-consequences of the postponement of childbearing will be of great interest as well, as witnessed also by the concentration of papers in this volume in this area of research. The implications 
of postponing fertility to extremely advanced ages (e.g., above 40 or 45 years for women) is vastly understudied, and further investigation could be expected on this issue. In the area of formal demography and the consequences of childbearing postponement on measurement, more will probably have to be done in connecting micro-level decision-making models and macro-level measurement models.

In conclusion, we feel that this issue of the Vienna Yearbook contains a diverse and stimulating set of articles. Future research on postponement of childbearing will certainly be inspired by and benefit from these contributions.

\section{References}

Aassve, A., F. C. Billari, and Z. Spéder. 2006. "Societal transition, policy changes and family formation: Evidence from Hungary." European Journal of Population 22: 127-152.

Baizán, P., A. Aassve, and F. C. Billari. 2004. "The interrelations between cohabitation, marriage and first birth in Germany and Sweden." Population and Environment 26, 6: 531-561.

Beck, U. 1992. Risk Society: Towards a New Modernity. London: Sage.

Bernardi, F. 2000. "Globalization, recommodification and social inequality: Changing patterns of early careers in Italy." Globalife Working Paper Series, No. 07, Faculty of Sociology, University of Bielefeld.

Bernhardt, E. and F. Goldscheider. 2006. "Gender equality, parenthood attitudes, and first births in Sweden." Vienna Yearbook of Population Research 2006: 19-39.

Bhaumik, S. 2002. "Does Economic Uncertainty Have an Impact on Decisions to Bear Children? Evidence from Eastern Germany." Working Paper WP-2002-037. Max Planck Institute for Demographic Research, Rostock.

Billari, F. C. and R. Borgoni. 2005. "Assessing the use of sample selection models in the estimation of fertility postponement effects." Statistical Methods and Applications 14(3): 389-402.

Billari, F. C. and H.-P. Kohler. 2004. "Patterns of low and lowest-low fertility in Europe." Population Studies 58(2): 161-176.

Billari, F. C. and D. Philipov. 2004. "Education and the transition to motherhood: A comparative analysis of Western Europe." European Demographic Research Papers Series 3. Vienna Institute of Demography, Vienna.

Billari, F. C., H.-P. Kohler, G. Andersson, and H. Lundström. 2006. "Pushing the age limit? Long-term Trends in Late Childbearing in Sweden." Working Paper, Max Planck Institute for Demographic Research, Rostock.

Blossfeld, H.-P. and J. Huinink. 1991. "Human capital investments or norms of role transition? How women's schooling and career affect the process of family formation.” American Journal of Sociology 97: 143-168.

Blossfeld, H-P., E. Klijzing, M. Mills, and K. Kurz (eds). 2005. Globalisation, Uncertainty, and Youth in Society. London: Routledge.

Bongaarts, J. and G. Feeney. 1998. "On the quantum and tempo of fertility." Population and Development Review 24(2): 271-291. 
Bongaarts, J. and G. Feeney. 2006. "The quantum and tempo of life-cycle events." Vienna Yearbook of Population Research 2006: 115-151.

Buchmann, M. 1989. The Script of Life in Modern Society. Entry into Adulthood in a Changing World. Chicago: University of Chicago Press.

Calot, G. 2001. "Mais qu'est-ce donc qu'un indicateur conjoncturel de fécondité?" Population 56: 325-327.

Cigno, A. and J. Ermisch. 1989. "A microeconomic analysis of the timing of first births." European Economic Review 33: 737-760.

Colombo, B. and G. Masarotto. 2000. "Daily fecundability: First results from a new data base." Demographic Research 3(5).

Commission of the European Communities. 2005. Green Paper "Confronting demographic change: a new solidarity between the generations." Brussels: Commission of the European Communities.

Dalla Zuanna, G. 2001. "The banquet of Aeolus: A familistic interpretation of Italy's lowest low fertility." Demographic Research 4: 131-162.

Dunson, D. B., Colombo, B., and D. D. Baird. 2002. "Changes with age in the level and duration of fertility in the menstrual cycle." Human Reproduction 17(5): 1399-1403.

Easterlin, R. A. 1980. Birth and Fortune: The Impact of Numbers on Personal Welfare. Chicago: University of Chicago Press.

Frejka, T. and J.-P. Sardon. 2004. Childbearing Prospects in Low-Fertility Countries: A Cohort Analysis. Dordrecht: Kluwer Academic Publishers.

Giddens, A. 1990. The Consequences of Modernity. Cambridge: Polity Press.

Goldstein, J. R. 2006. "How late can first births be postponed? Some illustrative population-level calculations." Vienna Yearbook of Population Research 2006: 153165.

Gustafsson, S. 2001. "Optimal age at motherhood. Theoretical and empirical considerations on postponement of maternity in Europe." Journal of Population Economics 14(2): 225-247.

Hajnal, J. 1965. "European Marriage Patterns on Perspective." In D. V. Glass and D. E. C. Eversley (eds.) Population in History : Essays in Historical Demography. London, Edward Arnold, pp. 101-143.

Hantrais, L., D. Philipov, and F. C. Billari. 2006. Policy implications of changing family formation. Strasbourg: Council of Europe.

Happel, S. K., J. K. Hill, and S. A. Low. 1984. "An economic analysis of the timing of childbirth.” Population Studies 38: 299-311.

Kohler, H.-P. and I. Kohler. 2002. "Fertility decline in Russia in the early and mid-1990s: The role of economic uncertainty and labour market crises." European Journal of Population 18(3): 233-262.

Kohler, H.-P. and J. A. Ortega. 2002b. "Tempo-adjusted period parity progression measures: Assessing the implications of delayed childbearing for fertility in Sweden, the Netherlands and Spain." Demographic Research 6(7): 145-190. «http://www.demographicresearch.org»

Kohler, H.-P., F. C. Billari, and J. A. Ortega. 2002. "The Emergence of Lowest-Low Fertility in Europe During the 1990s." Population and Development Review 28(4): 641-680.

Kravdal, Ø. 1994. "The importance of economic activity, economic potential and economic resources for the timing of first birth in Norway." Population Studies 48: 249-267. 
Larsen, U., and J. W. Vaupel. 1993. "Hutterite fecundability by age and parity: Strategies for frailty modelling of event histories." Demography 30(1): 81-102.

Leridon, H. 2004. "Can assisted reproduction technology compensate for the natural decline in fertility with age? A model assessment." Human Reproduction 19(7): 1549-1554.

Leridon, H. 2005. "A new estimate of permanent sterility by age: Sterility defined as the inability to conceive." Paper presented at the annual meeting of the Population Association of America, Philadelphia, PA, March 31-April 2, 2005.

Lesthaeghe, R. 1995. "The second demographic transition in Western countries: An interpretation." In K. O. Mason and A. M. Jensen (eds.) Gender and Family Change in Industrialized Countries. Oxford, Clarendon, pp. 17-62.

Lesthaeghe, R. 1998. "On theory development: Applications to the study of family formation." Population and Development Review 24: 1-14.

Lesthaeghe, R. and D. Van de Kaa. 1986. "Twee demografische transities?" In R. Lesthaeghe and D. Van de Kaa (eds.) Bevolking: Groei en Krimp. Deventer, Van Loghum Slaterus, pp. 9-24.

Liefbroer, A. C. 2005. "The impact of perceived costs and rewards of childbearing on entry into parenthood: Evidence from a panel study." European Journal of Population 21: 367-391.

Liefbroer, A. C. and M. Corijn. 1999. "Who, what, where, and when? Specifying the impact of educational attainment and labour force participation on family formation." European Journal of Population 15: 45-75.

Lutz, W. and V. Skirbekk. 2005. "Policies addressing the tempo effect in low-fertility countries." Population and Development Review 31(4): 699-720.

Lutz, W., B. C. O’Neill, and S. Scherbov. 2003. "Europe's population at a turning point." Science 299: 1991-1992.

Lutz, W., V. Skirbekk, and M. R. Testa. 2006. “The low-fertility trap hypothesis: Forces that may lead to further postponement and fewer births in Europe." Vienna Yearbook of Population Research 2006: 167-192.

Macura, M. and A. MacDonald. 2003. "Fertility and fertility regulation in Eastern Europe: from the socialist to the post-socialist era." In I. E. Kotowska and J. Józwiak (eds.) Population of Central and Eastern Europe. Challenges and Opportunities. Warsaw, Statistical Publishing Establishment, pp. 35-90.

Matsuo, H. 2006. "The postponement of motherhood and its child health consequences: Birth weight and weight gain during the first year of life." Vienna Yearbook of Population Research 2006: 91-114.

McArdle, P. F., T. I. Pollin, J. R. O'Connell, J. D. Sorkin, R. Agarwala, A. A. Schäffer, E. A. Streeten, T. M. King, A. R. Shuldiner, and B. D. Mitchell. 2006. "does having children extend life span? A Genealogical study of parity and longevity in the Amish.” Journal of Gerontology Series A: Biological Sciences and Medical Sciences 61: 190-195.

McDonald, P. 2006. "An assessment of policies that support having children from the perspectives of equity, efficiency and efficacy." Vienna Yearbook of Population Research 2006: 213-234.

Monnier, A. and J. Rychtarikova. 1992. "The division of Europe into east and west." Population: An English Selection 4: 129-159.

Morgan, S. P. and M. G. Taylor. 2006. "Low fertility at the turn of the twenty-first century." Annual Review of Sociology 32: 375-299. 
Mueller, U. 2004. "does late reproduction extend the life span? Findings from European royalty." Population and Development Review 30(3): 449-466.

Müller, H.-G., J.-M. Chiou, J. R. Carey, and J.-L. Wang. 2002. "Fertility and life span. Late children enhance female longevity." Journal of Gerontology Series A: Biological Sciences and Medical Sciences 57: 202-206.

Ní Bhrolchain, M. 1992. "Period paramount? A critique of the cohort approach to fertility." Population and Development Review 18: 599-629.

Ortega, J. A. and H.-P. Kohler. 2002. "measuring low fertility: Rethinking demographic methods." Working Paper WP 2002-001, Max Planck Institute for Demographic Research.

Philipov, D. 2001. "Low fertility in Central and Eastern Europe: Culture or economy?" Paper presented at the IUSSP working group on low fertility Conference, Tokyo 2001.

Philipov, D. and J. Dorbritz. 2003. Demographic consequences of economic transition in countries of Central and Eastern Europe. Population Studies, No. 39, Strasbourg: Council of Europe Publishing.

Philipov, D., Z. Spéder, and F. C. Billari. 2006. "Soon, later or ever? The impact of anomie and social capital on fertility intentions in Bulgaria (2002) and Hungary (2001)." Population Studies 60(3): 289-308.

Ranjan, P. 1999. "Fertility behaviour under income uncertainty." European Journal of Population 15: 25-43.

Rizzi, E. and A. Rosina. 2006. "Does sex matter? Ageing and ability to conceive." Vienna Yearbook of Population Research 2006: 77-90.

Sobotka, T. 2004a. Postponement of childbearing and low fertility in Europe. Amsterdam: Dutch University Press.

Sobotka, T. 2004b. "Is lowest-low fertility in Europe explained by the postponement of childbearing?" Population and Development Review 30(2): 195-220.

Surkyn, J and R Lesthaeghe. 2004. "Value orientations and the second demographic transition (SDT) in Northern, Western and Southern Europe: An update." Demographic Research, Special Collection 3: 45-75.

Testa, M. R. and L. Toulemon. 2006. "Family formation in France: Individual preferences and subsequent outcomes." Vienna Yearbook of Population Research 2006: 41-75.

Thornton, A. 2001. "The developmental paradigm, reading history sideways, and family change." Demography 38(4): 449-465.

Thornton, A., W. G. Axinn, and J. D. Teachman. 1995. "The influence of school enrollment and accumulation on cohabitation and marriage in early adulthood." American Sociological Review 60: 762-774.

UNECE. 2000. "Fertility decline in the transition economies, 1989-1998: economic and social factors revisited." Economic Survey of Europe 2000: 189-207.

Van de Kaa, D. J. 1987. “Europe's Second Demographic Transition.” Population Bulletin 42(1). Washington, DC: Population Reference Bureau.

Van de Kaa, D. J. 1997. "Options and sequences: Europe's demographic patterns." Nethur Demography Paper 39.

Van de Kaa, D. J. 2001. "Postmodern fertility preferences: From changing value orientation to new behavior.” In.: R. A. Bulatao and J. B. Casterline (eds.), Global Fertility Transition. Supplement to Population and Development Review, Vol. 27, pp. 290-331. 
Van de Kaa, D. J. 2006. "Temporarily new: On low fertility and the prospect of pro-natal policies." Vienna Yearbook of Population Research 2006: 193-211.

Vikat, A., Spéder, Z., Beets, G., Billari, F. C., Bühler, C., Désesquelles, A., Fokkema, T., Hoem, J. M., MacDonald, A., Neyer, G., Pailhé, A. Pinnelli, A., and A. Solaz. 2006. "Generations and Gender Survey (GGS): Towards a better understanding of relationships and processes in the life course." Paper presented at the European Population Conference, 2006, Liverpool.

Yi, Z. and J. W. Vaupel. 2004. "Association of late childbearing with healthy longevity among the oldest-old in China." Population Studies 58(1): 37-53. 